EPJ Web of Conferences 110,01071 (2016)

DOI: 10.1051/epjconf/201611001071

(C) Owned by the authors, published by EDP Sciences, 2016

\title{
INFLUENCE OF CONDITIONS OF HEATING UP ON INTEGRAL CHARACTERISTICS OF HEATTRANSFER IN THE SENSITIVE ELEMENT OF THE THERMOCONJUGATE SENSOR
}

\author{
Yuliana K. Atroshenko ${ }^{1,}$, , Anna V. Abramova ${ }^{1}$ \\ ${ }^{1}$ National Research Tomsk Polytechnic University, 634050 Tomsk, Russia
}

\begin{abstract}
Heattransfer models in a sensitive element of the thermoconjugate temperature sensor in different conditions of heating up of the thermocouple are developed. Tasks of heat conduction for cases when on outline borders of the thermocouple conditions of I, II and III kinds are set are considered. Dependences of necessary duration of heating up of the thermocouple for different values of a heat flux to outline borders of a sensitive element for thermocouples of types $\mathrm{K}, \mathrm{L}$ and $\mathrm{E}$, distribution of temperature in the thermocouple in different conditions of heating up are received.
\end{abstract}

\section{Introduction}

Thermoconjugate sensors are used to temperature measurement in many industries, including in mechanical engineering, power engineering, the food industry and others [1-3]. Often in practice it is necessary to use thermoelectric transformers of industrial execution which construction is intended for protection of thermoelectrodes and a thermocouple junction against negative impact of a work environment [3]. However complication of construction of the transformer leads to increase in a thermal inertance of the sensor and has impact on integral characteristics of process of heattransfer in a sensitive element of the sensor in case of its heating up [4]. Influence on integral characteristics of heattransfer external conditions of heating up of the sensor can also have impact. In that case when the sensor is located in the environment with continuous temperature, on outline borders of the sensor distribution of temperature is set (that is the problem is solved with boundary conditions of the I kind). In case of process modeling of heattransfer of temperature measurement thermocouples in hightemperature furnaces on boundaries set a heat flux (a condition of the II kind). However the greatest distribution in tasks heating engineers was gained by a condition in case of which correlation between a heat flow due to heat conduction from a solid wall of a protective cover of the thermocouple and a heat flux from environment at the expense of a temperature pressure (boundary conditions of the III kind) is set.

The purpose of the real operation is simulation of a sensitive element of the thermoelectric transformer with an isolated seal in different conditions of heating up.

\footnotetext{
${ }^{a}$ Corresponding author: julie55@tpu.ru
} 


\section{Physical model of heat transfer}

Conditions of measurements (fig. 1) in which on outline borders of area of the solution of the task of heattransfer in a sensitive element of the thermocouple the heat flux of q (boundary conditions of the II kind) and distribution of temperature on boundary (boundary conditions of the I kind) is set are considered.
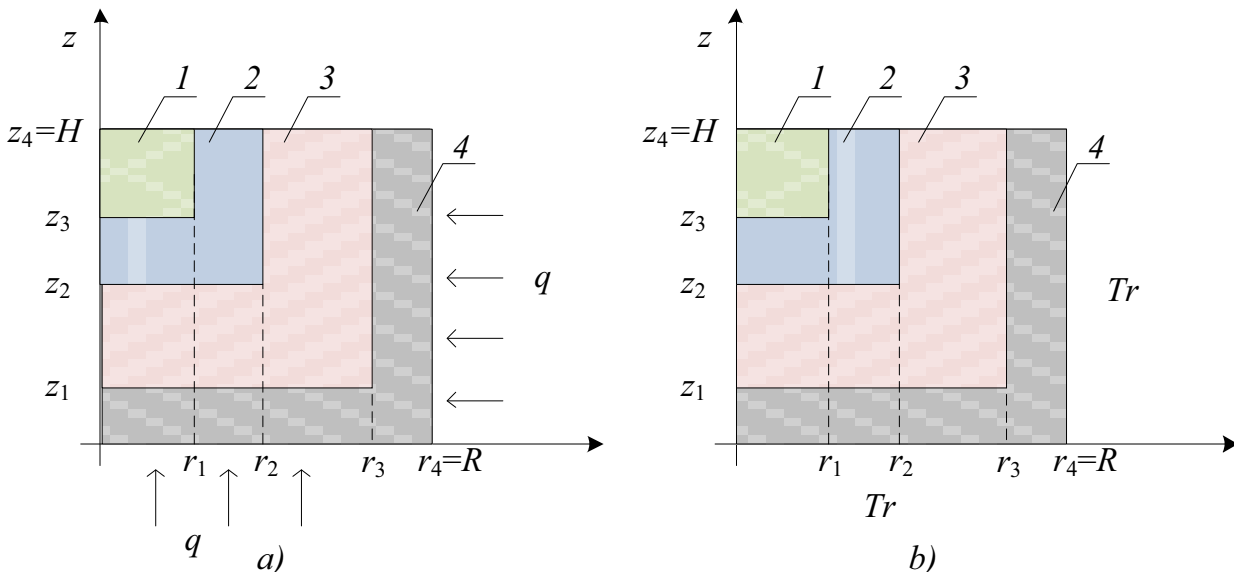

b)

Figure 1. The task of heattransfer in a sensitive element of the thermocouple: on outline borders boundary conditions of the II kind are set (and), on outline borders boundary conditions of the I kind are set $(b), 1-$ thermocouple junction; 2 - powder $\mathrm{Al}_{2} \mathrm{O}_{3} ; 3$ - protective cover; 4 - air gap.

The following assumptions are accepted in case of numerical modeling:

1) Heat-physical characteristics of the materials entering area of the solution of the task don't depend on temperature;

2) Thermocouple is cylindrical form.

The end of process of heating up was defined at the time of achievement by a thermocouple junction of temperature, other than an allowed error measured on value. Values of allowed errors are given in table 1 .

Table 1 Limits of allowed errors of thermocouple [5].

\begin{tabular}{|c|l|}
\hline Thermocouple's type & Permissible deviation limit from rated direct current characteristic, ${ }^{\circ} \mathrm{C}$ \\
\hline$L(2$ tolerance class $)$ & $\begin{array}{l} \pm 2,5 \text { in the range of temperatures from }-40 \text { to } 300{ }^{\circ} \mathrm{C} ; \\
\pm 0,0075 \cdot t \text { in the range of temperatures from } 300 \text { to } 800{ }^{\circ} \mathrm{C}\end{array}$ \\
\hline$E$ (2 tolerance class $)$ & $\begin{array}{l} \pm 2,5 \text { in the range of temperatures from }-40 \text { to } 375{ }^{\circ} \mathrm{C} ; \\
\pm 0,0075 \cdot t \text { in the range of temperatures from } 375 \text { to } 800{ }^{\circ} \mathrm{C}\end{array}$ \\
\hline$K(2$ tolerance class $)$ & $\begin{array}{l} \pm 2,5 \text { in the range of temperatures from }-40 \text { to } 333{ }^{\circ} \mathrm{C} ; \\
\pm 0,0075 \cdot t \text { in the range of temperatures from } 333 \text { to } 1000{ }^{\circ} \mathrm{C}\end{array}$ \\
\hline
\end{tabular}

For area solutions of the task (fig. 1) are made the following sizes: $\mathrm{H}=5 \mathrm{~mm} ; \mathrm{R}=5 \mathrm{~mm}$.

\section{Mathematical model and decision methods}

Process of heattransfer in the considered system (fig. 1) is described by system of differential equations:

$$
c_{1} \rho_{1} \frac{\partial T_{1}}{\partial t}=\lambda_{1}\left(\frac{\partial^{2} T_{1}}{\partial r^{2}}+\frac{1}{r} \frac{\partial T_{1}}{\partial r}+\frac{\partial^{2} T_{1}}{\partial z^{2}}\right), t>0,0<r<r_{1}, z_{4}<z<H
$$




$$
\begin{aligned}
& c_{2} \rho_{2} \frac{\partial T_{2}}{\partial t}=\lambda_{2}\left(\frac{\partial^{2} T_{2}}{\partial r^{2}}+\frac{1}{r} \frac{\partial T_{2}}{\partial r}+\frac{\partial^{2} T_{2}}{\partial z^{2}}\right), t>0,0<r<r_{2}, z_{2}<z<z_{3}, r_{1}<r<r_{2}, z_{3}<z<H \\
& c_{3} \rho_{3} \frac{\partial T_{3}}{\partial t}=\lambda_{3}\left(\frac{\partial^{2} T_{3}}{\partial r^{2}}+\frac{1}{r} \frac{\partial T_{3}}{\partial r}+\frac{\partial^{2} T_{3}}{\partial z^{2}}\right), t>0,0<r<r_{3}, z_{1}<z<z_{2} ; r_{2}<r<r_{3}, z_{2}<z<H \\
& c_{4} \rho_{4} \frac{\partial T_{4}}{\partial t}=\lambda_{4}\left(\frac{\partial^{2} T_{4}}{\partial r^{2}}+\frac{1}{r} \frac{\partial T_{4}}{\partial r}+\frac{\partial^{2} T_{4}}{\partial z^{2}}\right), t>0,0<r<r_{4}, 0<z<z_{1} ; r_{3}<r<r_{4}, z_{1}<z<H
\end{aligned}
$$

Where $\mathrm{r}$ - radial coordinate, $\mathrm{m}$; $\mathrm{z}$ - axial coordinate, $\mathrm{m} ; \rho$ - density, $\mathrm{kg}$ / $\mathrm{m} 3$; $\mathrm{c}$ - specific heat capacity, $\mathrm{J} /\left(\mathrm{kg} \cdot{ }^{\circ} \mathrm{C}\right) ; \lambda$ - coefficient of heat conduction, $\mathrm{W} /\left(\mathrm{m} \cdot{ }^{\circ} \mathrm{C}\right)$; indexes: 1 - thermocouple's junction, 2 - powder of an oxide of aluminum, 3 - a protective cover, 4 - air.

Boundary conditions on inner and outline borders are given in table 2.

\begin{tabular}{|c|c|c|c|}
\hline Edge conditions & $\begin{array}{c}\text { Decision area } \\
\text { boundary }\end{array}$ & Edge conditions & $\begin{array}{c}\text { Decision area } \\
\text { boundary }\end{array}$ \\
\hline $\begin{array}{l}T_{1}\left(r_{1}, z\right)=T_{2}\left(r_{1}, z\right) \\
-\left.\lambda_{1} \frac{\partial T_{1}}{\partial r}\right|_{r=r_{1}}=-\left.\lambda_{2} \frac{\partial T_{2}}{\partial r}\right|_{r=r_{1}}\end{array}$ & $\left(z_{3}<z<H\right)$ & $\begin{array}{l}T_{1}\left(r, z_{3}\right)=T_{2}\left(r, z_{3}\right) \\
-\left.\lambda_{1} \frac{\partial T_{1}}{\partial z}\right|_{z=z_{3}}=-\left.\lambda_{2} \frac{\partial T_{2}}{\partial z}\right|_{z=z_{3}}\end{array}$ & $\left(0<r<r_{1}\right)$ \\
\hline $\begin{array}{l}T_{2}\left(r_{2}, z\right)=T_{3}\left(r_{2}, z\right) \\
-\left.\lambda_{2} \frac{\partial T_{2}}{\partial r}\right|_{r=r_{2}}=-\left.\lambda_{3} \frac{\partial T_{3}}{\partial r}\right|_{r=r_{2}}\end{array}$ & $\left(z_{2}<z<H\right)$ & $\begin{array}{l}T_{2}\left(r, z_{2}\right)=T_{3}\left(r, z_{2}\right) \\
-\left.\lambda_{2} \frac{\partial T_{2}}{\partial z}\right|_{z=z_{2}}=-\left.\lambda_{3} \frac{\partial T_{3}}{\partial z}\right|_{z=z_{2}}\end{array}$ & $\left(0<r<r_{2}\right)$ \\
\hline $\begin{array}{l}T_{3}\left(r_{3}, z\right)=T_{4}\left(r_{3}, z\right) ; \\
-\left.\lambda_{3} \frac{\partial T_{3}}{\partial r}\right|_{r=r_{3}}=-\left.\lambda_{4} \frac{\partial T_{4}}{\partial r}\right|_{r=r_{3}}\end{array}$ & $\left(z_{1}<z<H\right)$ & $\begin{array}{l}T_{3}\left(r, z_{1}\right)=T_{4}\left(r, z_{1}\right) \\
-\left.\lambda_{3} \frac{\partial T_{3}}{\partial z}\right|_{z=z_{1}}=-\left.\lambda_{4} \frac{\partial T_{4}}{\partial z}\right|_{z=z_{1}}\end{array}$ & $\left(0<r<r_{3}\right)$ \\
\hline \multicolumn{4}{|c|}{ Edge statements of the problem which area of the decision is given in a figure $1, a$} \\
\hline$\frac{\partial T}{\partial z}=0$ & $(z=H)$ & $\frac{\partial T}{\partial r}=0$ & $(r=0)$ \\
\hline$-\lambda_{4} \frac{\partial T_{4}}{\partial z}=q$ & $(z=0)$ & $-\lambda_{4} \frac{\partial T_{4}}{\partial r}=q$ & $(r=R)$ \\
\hline \multicolumn{4}{|c|}{ Edge statements of the problem which area of the decision is given in a figure $1, \sigma$} \\
\hline$\frac{\partial T}{\partial z}=0$ & $(z=H)$ & $\frac{\partial T}{\partial r}=0$ & $(r=0)$ \\
\hline$T=T r$ & $(z=0)$ & $T=\operatorname{Tr}$ & $(r=R)$. \\
\hline
\end{tabular}

Table 2 Boundary conditions of the task of heattransfer with the given external heat flux and boundary heat exchange.

The area of the solution of the task (fig. 1) is broken into the uniform grid consisting of 200 nodes. The slot pitch on radial and axial coordinates is equal $2,5 \cdot 10^{-2} \mathrm{~mm}$. The step on a temporal grid changed in the range from $10^{-4}$ to $10^{-2} \mathrm{sec}$ for reduction of volume of computation and increase of accuracy of the decision.

System of equations 1-4 with the appropriate initial and boundary conditions decided using a method of finite differences [6]. The solution of the difference analogs of the differential equations representing linear algebraic equations was carried out by a local and one-dimensional method [6]. 
The pro-race method was applied to the decision of system of the difference equations on the basis of the implicit four-point diagram [6].

The conservatism verification of applied difference schemes was conducted to estimate the confidence of numerical simulation results similar to [7-9]) and the comparison with experiment results was accomplished.

\section{Results and discussion}

Mathematical modelling were carried out at parameters [10-11]: thermocouple junction (type $L$ ): $\lambda_{1}=24,75 \mathrm{~W} /\left(\mathrm{m} \cdot{ }^{\circ} \mathrm{C}\right) ; C_{1}=713 \mathrm{~J} /\left(\mathrm{kg} \cdot{ }^{\circ} \mathrm{C}\right) ; \rho_{1}=8920 \mathrm{~kg} / \mathrm{m}^{3} ;$ thermocouple junction (type $\left.K\right): \lambda_{1}=33,1$ $\mathrm{W} /\left(\mathrm{m} \cdot{ }^{\circ} \mathrm{C}\right) ; C_{1}=768 \mathrm{~J} /\left(\mathrm{kg} \cdot{ }^{\circ} \mathrm{C}\right) ; \rho_{1}=8825 \mathrm{~kg} / \mathrm{m}^{3}$; thermocouple junction (type $E: \lambda_{1}=22,5 \mathrm{~W} /\left(\mathrm{m} \cdot{ }^{\circ} \mathrm{C}\right)$; $C_{1}=435 \mathrm{~J} /\left(\mathrm{kg} \cdot{ }^{\circ} \mathrm{C}\right) ; \rho_{1}=8815 \mathrm{~kg} / \mathrm{m}^{3}$; insulating cap: $\lambda_{2}=16 \mathrm{~W} /\left(\mathrm{m} \cdot{ }^{\circ} \mathrm{C}\right) ; C_{2}=3480 \mathrm{~J} /\left(\mathrm{kg} \cdot{ }^{\circ} \mathrm{C}\right) ; \rho_{2}=3800$

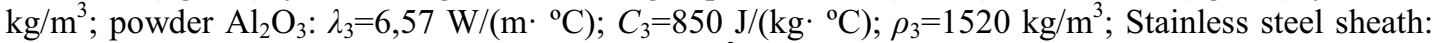
$\lambda_{4}=15 \mathrm{~W} /\left(\mathrm{m}^{\circ}{ }^{\circ} \mathrm{C}\right) ; C_{4}=462 \mathrm{~J} /\left(\mathrm{kg} \cdot{ }^{\circ} \mathrm{C}\right) ; \rho_{4}=7900 \mathrm{~kg} / \mathrm{m}^{3}$.

Dependences of minimum necessary period of operation of the thermoelectric transformer of values of heat fluxes of different values are shown in a figure 2.

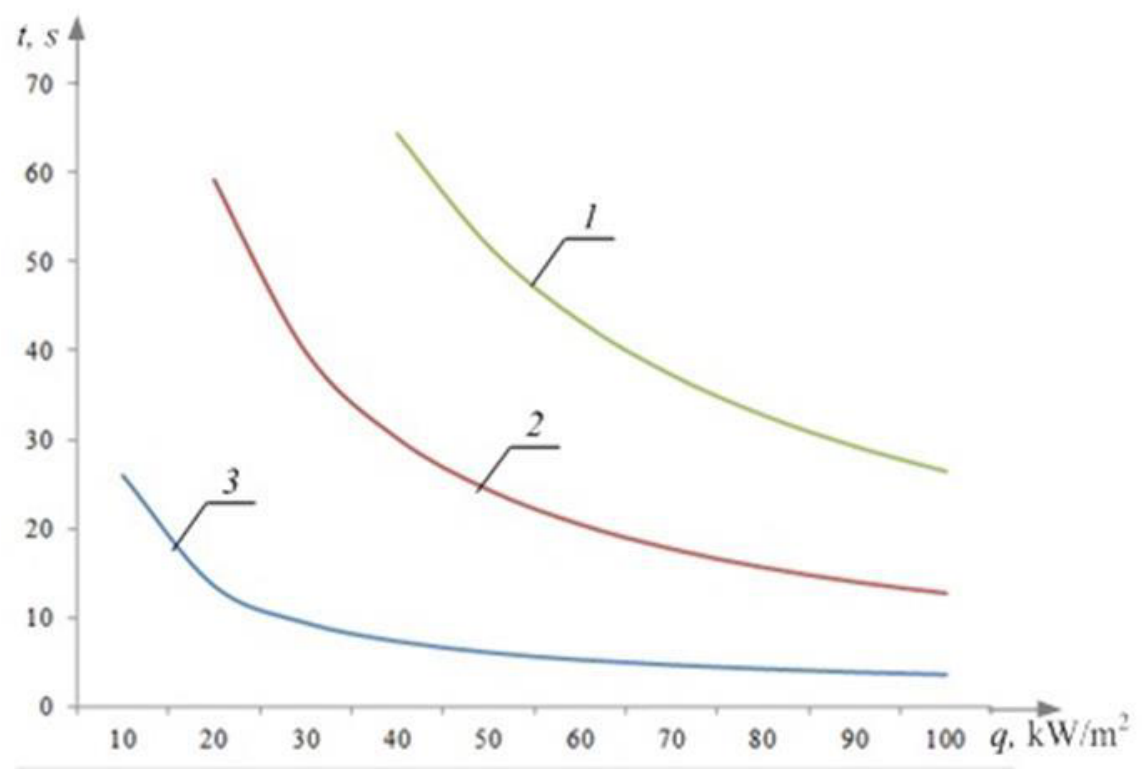

Figure 2. Dependence of minimum necessary duration of operation of the thermocouple in case of measurement of temperatures $580^{\circ} \mathrm{C}(1), 280{ }^{\circ} \mathrm{C} \mathrm{(2),} 80^{\circ} \mathrm{C}$ (3) from a heat flux of $\mathrm{q}$ to outline borders of a sensitive element.

Operations of the thermocouple necessary for duration in case of temperature measurement $80{ }^{\circ} \mathrm{C}$ for types $\mathrm{K}, \mathrm{L}, \mathrm{E}$ are given in table 3 .

Table 3. Dependences of necessary duration of operation of the thermocouple in case of temperature measurement from value of a heat flux of $\mathrm{q}$.

\begin{tabular}{|c|c|c|c|}
\hline \multirow{2}{*}{ heat flux $q, \mathrm{~kW} / \mathrm{m}^{2}$} & \multicolumn{3}{|c|}{ Duration of operation of the thermocouple, sec } \\
\cline { 2 - 4 } & Type K & Type $L$ & Type $E$ \\
\hline 10 & 25,990 & 25,960 & 25,688 \\
\hline 20 & 13,544 & 13,530 & 13,356 \\
\hline 30 & 9,395 & 9,386 & 9,245 \\
\hline 40 & 7,320 & 7,315 & 7,190 \\
\hline
\end{tabular}




\begin{tabular}{|c|c|c|c|}
50 & 6,076 & 6,071 & 5,956 \\
\hline 60 & 5,245 & 5,242 & 5,134 \\
\hline 70 & 4,651 & 4,649 & 4,546 \\
\hline 80 & 4,205 & 4,203 & 4,104 \\
\hline 90 & 3,857 & 3,856 & 3,759 \\
\hline 100 & 3,577 & 3,576 & 3,483 \\
\hline
\end{tabular}

From a figure 2 and table 2 it is visible that in case of increase in heating intensity (increase in a heat flux) time of establishment of indications of the temperature sensor considerably decreases. In case of value of a heat flux of $\mathrm{q}=100$ of $\mathrm{kW} / \mathrm{sq} . \mathrm{m}$ minimum necessary duration of operation of the thermocouple is comparable with znacheny, received in the conditions of action on outline borders by $\mathrm{r}=\mathrm{R}$ and $\mathrm{z}=0$ of continuous temperature of $\mathrm{t}=80^{\circ} \mathrm{C}$ on outline borders of a sensitive element. Distribution of temperature in a sensitive element of the thermocouple for boundary conditions of I and II kind is shown, respectively, in figures 3 and 4.

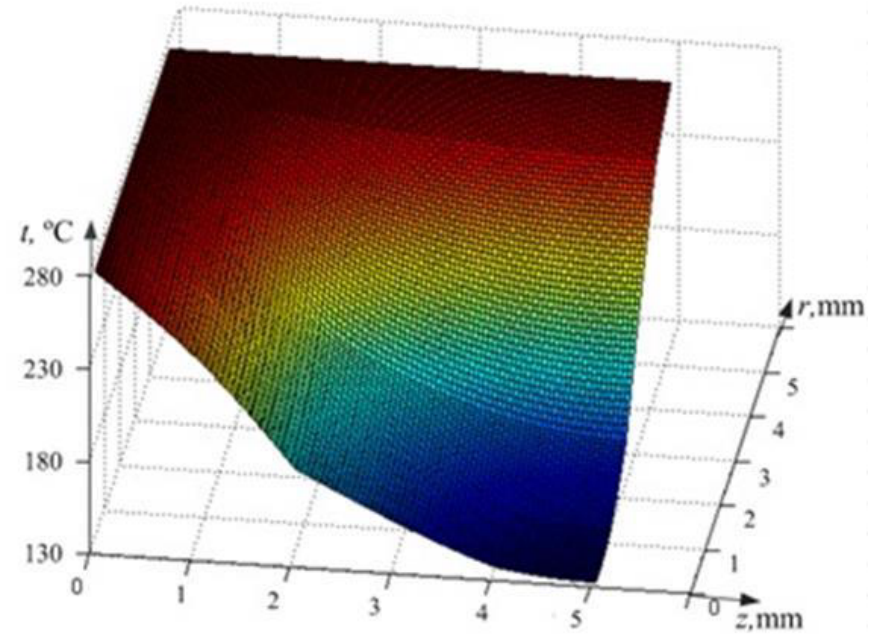

Figure 3. Temperature field in the thermoelectric transformer of $\mathrm{K}$ type in case of temperature measurement of a surface of a sample $280^{\circ} \mathrm{C}$ in case of the job of temperature on outline borders of the thermocouple.

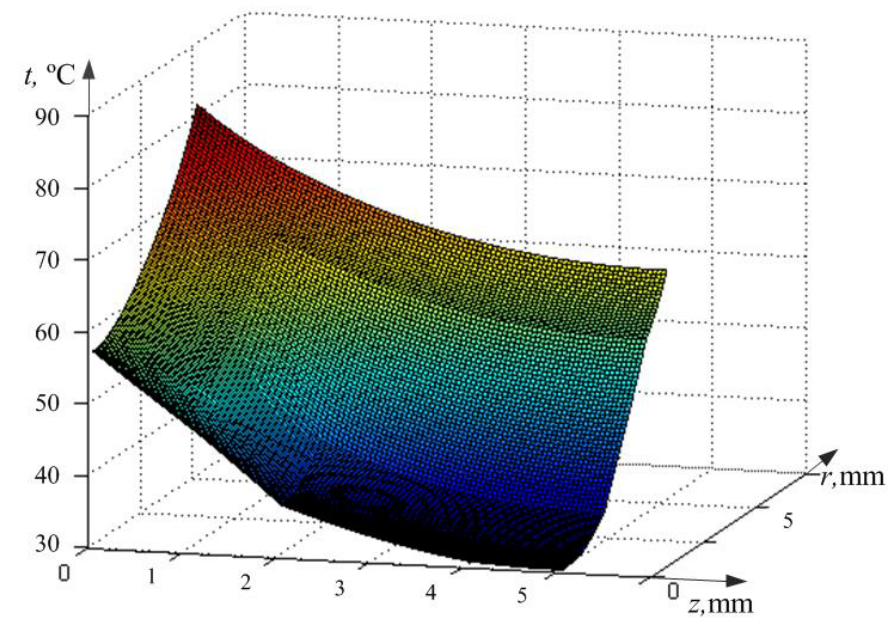

Figure 4. Temperature field in the thermoelectric transformer of $\mathrm{K}$ type in case of temperature measurement of a surface of a sample $280^{\circ} \mathrm{C}$ in case of action of a heat flux on outline borders of the thermocouple. 
From figures 3 and 4 it is visible that if on boundaries of a sensitive element distribution of temperature is set (a figure 3), i.e. edge conditions of the I kind, heating of the considered area are used occurs practically uniformly in the directions $r$ and $z$. If on boundaries of area of the decision the heat flux (edge conditions of the II kind), distribution of temperature a little nonuniformly is set.

The integral characteristics of heat transfer in the thermocouple received with use of boundary conditions of the III kind show, what even in actual practice heat exchange with an external environment (change of coefficient of heat exchange $\kappa$ in the range from 0 to $30 \mathrm{~W} /\left(\mathrm{sq} . \mathrm{m} \cdot{ }^{\circ} \mathrm{C}\right.$ ) the operations of the thermocouple required duration can be very big in case of imperfect contact of a thermocouple junction with a surface of object of measurement.

\section{Conclusion}

1. Heat transfer models in a sensitive element of the thermocouple are developed for cases, when on outline borders of the thermocouple for three cases:

- distribution of temperature is set;

- the heat flux of $\mathrm{q}$ is enclosed;

- Characteristics of heat exchange with environment are set.

2. It is set that duration of execution of temperature measurement for receiving results within blundered decreases with increase in the enclosed heat flux. In case of the intensity of heating up corresponding to a heat flux value of $100 \mathrm{~kW} / \mathrm{sq} . \mathrm{m}$ the received duration of heating up it is comparable to the results received in the conditions of the job on boundaries of continuous temperature $80^{\circ} \mathrm{C}$.

\section{Acknowledgments}

This work was supported by State task "Science" (Code of the federal target scientific and technical program 2.1410.2014)

\section{References}

1. H. Mohammed, H. Salleh, M.Z. Yusoff, Thermal science, 11, № 3, 49 (2007)

2. J.I. Sylvia, J.S. Clement Ravi Chandar, K. Velusamy, Nucl. Eng. Des., 275, 154 (2014)

3. Y. K. Atroshenko, I.P. Ozerova, P.A.Strizhak, Adv. Mater. Res., 1040, 965 (2014)

4. Y.K. Atroshenko and P.A. Strizhak, EPJ Web of Conferences, 82, Article Number 01061 (2015)

5. IEC 60584-2. International standard. Thermocouples. Part 2: Tolerances, 1989

6. A.A. Samarskii, The Theory of Difference Schemes (Marcel Dekker, Inc., USA, 2001)

7. G.V. Kuznetsov G.V. and P.A. Strizhak, Int. J. Heat Mass Transfer, 53, 923 (2010)

8. D.O. Glushkov, G.V. Kuznetsov, P.A. Strizhak, Russian Journal of Physical Chemistry B., 1000 (2011)

9. D.O. Glushkov, P.A. Strizhak, J. Eng. Thermophys., 69 (2012).

10. E.V. Zinovyev, Thermal properties of metals at high temperatures (Metallurgy, Moscow, 1989)

11. R. Hultgren, Selected Values of the Thermodynamic Properties of Binary Alloys (USA, American Society for Metals, 1973) 